\title{
Laparoscopic Myomectomy for Multiple Submucous Myomas
}

\author{
Rakesh Sinha, Meenakshi Sundaram, Pratima Kadam, Seema Gupta, Nupur Sood, Sharda Adlakha \\ Bombay Endoscopy Academy and Center for Minimally Invasive Surgery, Beams Hospital, Mumbai, Maharashtra, India
}

Correspondence: Meenakshi Sundaram, 674, 16th Cross Road, Behind Khar Gymkhana, Khar Pali, Khar (W), Mumbai-400052 Maharashtra, India, Phone: 91-22-26463606, 91-22-26464049, 91-22-26464056, Fax: 91-22-26463887, e-mail: drmeena25@yahoo.com

\section{ABSTRACT}

We report an interesting case of multiple submucous fibroids which was removed by laparoscopic myomectomy. The patient presented with severe menorrhagia and a large uterus of clinically 24 weeks size. She was 29 years and nulliparous. The ultrasonography showed multiple echoes in the endometrial cavity. We did a diagnostic hysteroscopy and found the uterine cavity studded with multiple fibroids of varying sizes. We did a laparoscopy and removed 64 submucous fibroids laparoscopically. We report this interesting case where we removed the submucous fibroids laparoscopically in a single sitting. This reduces the complications of hysteroscopic myomectomy for such large and multiple submucous fibroids. Medline search did not reveal any report of laparoscopic removal of submucous fibroids.

Keywords: Submucous myomas, Laparoscopic myomectomy, Hysteroscopic myomectomy.

\section{INTRODUCTION}

Uterine leiomyomas are one of the most common benign smooth muscle tumors in women, with a prevalence of 20 to $40 \%$ in women over the age of 35 years. ${ }^{1}$ Submucous myomas are those that most frequently cause menorrhagia and infertility. ${ }^{2}$ Hysteroscopic myomectomy is the therapeutic option for submucous myomas with abnormal uterine bleeding and/or infertility.

Uterine bleeding, perforation and fluid overload are major complications which can occur during hysteroscopic myomectomy, if not performed by an experienced surgeon. Prolonged surgery can cause fluid overload leading to electrolyte imbalances and its subsequent complications. ${ }^{3}$ This can occur during hysteroscopic resection of large submucous myomas. If the size of the submucous myoma is more than $5 \mathrm{~cm}$ on ultrasonography, we prefer to remove them by laparoscopic myomectomy. We report a case of multiple submucous fibroids which were removed by laparoscopic myomectomy.

\section{CASE REPORT}

A 29-year-old nulliparous patient presented to our hospital with complaints of severe menorrhagia and infertility for 2 years. Her hemoglobin levels were $5.9 \mathrm{gm} \%$. She had not undergone any surgeries previously. There were no previous medical ailments. Clinical examination revealed a 24 weeks' size uterine mass which was uniformly enlarged. Ultrasonography revealed an enlarged uterus with multiple echoes in the endometrial

Date of Received: 17-08-10

Date of Acceptance: 04-07-11

Date of Publication: May 2011 lining, the largest were measuring $6 \times 5 \mathrm{~cm}$ and $5 \times 4 \mathrm{~cm}$. Both the ovaries were normal on ultrasonography. She received three units of packed cell transfusion before the procedure.

\section{OPERATIVE PROCEDURE}

The surgery was performed under general anesthesia with the patient in modified lithotomy position. A diagnostic hysteroscopy was done. It showed multiple submucous fibroids extending through the entire endometrial lining (Figs 1A and B). The largest was from the anterior wall. In view of prolonged surgical time for hysteroscopic myomectomy and the risk of perforation, we decided to proceed laparoscopically.

Externally, the mass was extending up to the umbilicus. Veress needle was inserted at the Palmer's point. The Palmer's point $^{4}$ (a point $3 \mathrm{~cm}$ below the left costal margin in the midclavicular line) is a safe zone in all patients other than those with splenomegaly.

After insufflation with carbon dioxide, a $5 \mathrm{~mm}$ trocar is inserted blindly in the left upper quadrant above the level of the umbilicus almost close to the Palmer's point. A $10 \mathrm{~mm}$ optical port is inserted supraumbilically. This port is inserted under vision through the left lateral port. We used three $5 \mathrm{~mm}$ accessory ports. The port placed initially in the left lateral upper quadrant is used as the first accessory port. The second port is placed under vision in the right lateral upper quadrant and the third port is placed in the left lateral lower quadrant.

At laparoscopy, the uterus was uniformly enlarged (Fig. 2). There was no evidence of subserosal fibroids. The adnexa were normal. The uterovesical fold of peritonuem was opened and both the uterine arteries were ligated. A horizontal incision was made on the fundus of the uterus. As the incision was widened 
and deepened, multiple submucous fibroids could be visualized (Fig. 3). We started enucleation of the fibroids one after another (Fig. 4). The left upper port was converted to $15 \mathrm{~mm}$ port and the morcellator was introduced. The fibroids were directly enucleated from the endometrial cavity by morcellation (Fig. 5). Uterine artery ligation cuts off the blood supply to the fibroids and hence minimal bleeding was encountered during enucleation and direct morcellation. ${ }^{5}$ About 64 fibroids were removed from the uterine cavity (Fig. 6). All the fibroids were morcellated and removed. The endometrial lining was reposited.The myometrial bed was sutured in two layers: First mattress to obliterate the dead space and second figure of eight

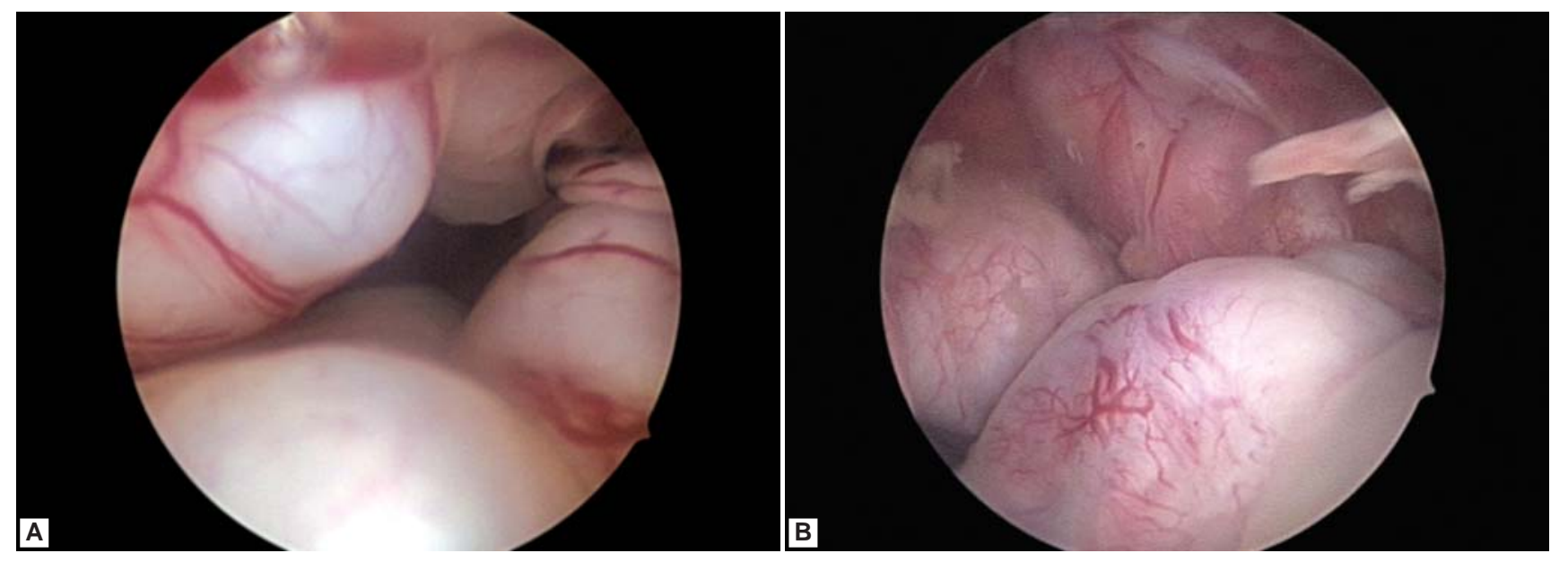

Figs 1 A and B: Multiple submucous fibroids on hysteroscopy

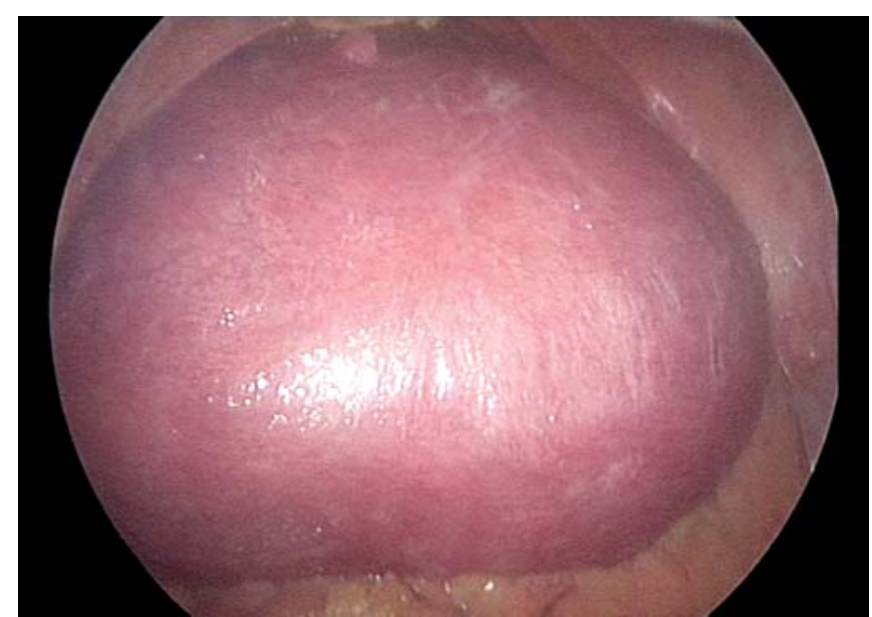

Fig. 2: Large uterus viewed laparoscopically

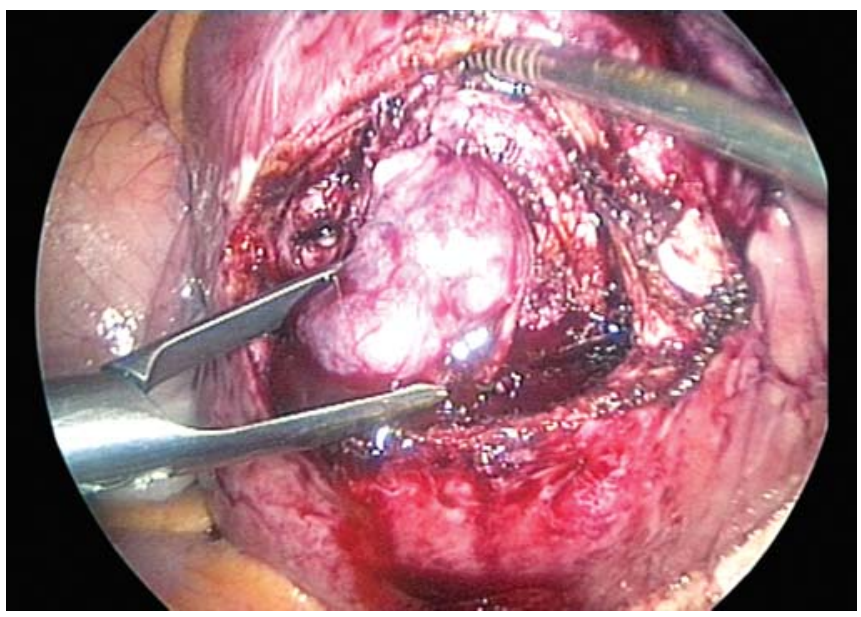

Fig. 4: Enucleation of myomas

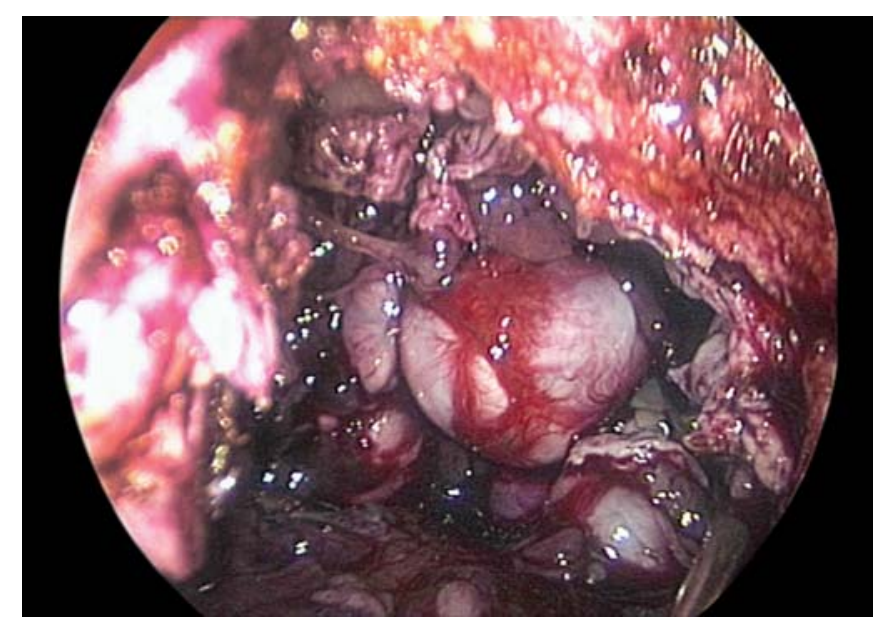

Fig. 3: Uterine cavity and multiple submucous fibroids visualized

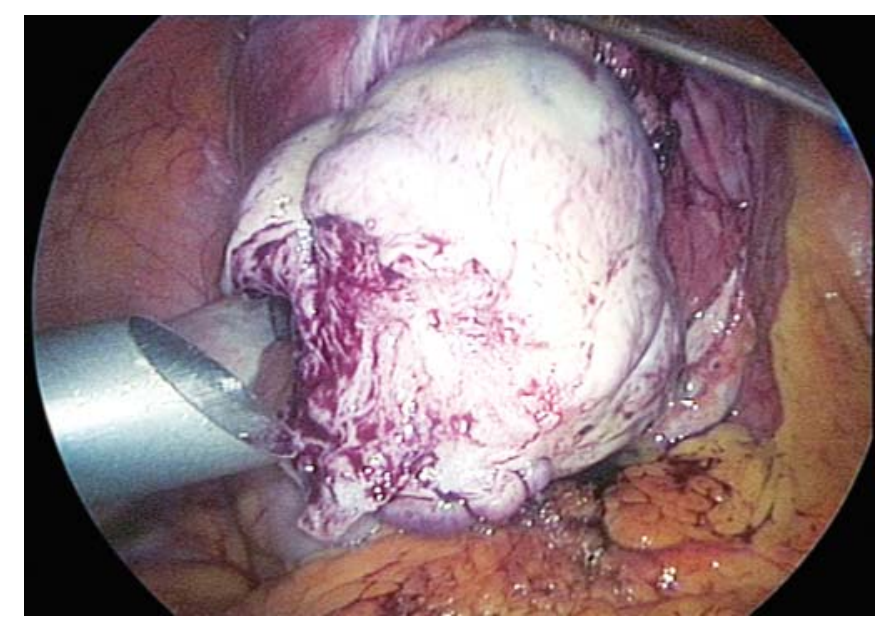

Fig. 5: Morcellation of enucleated myoma 


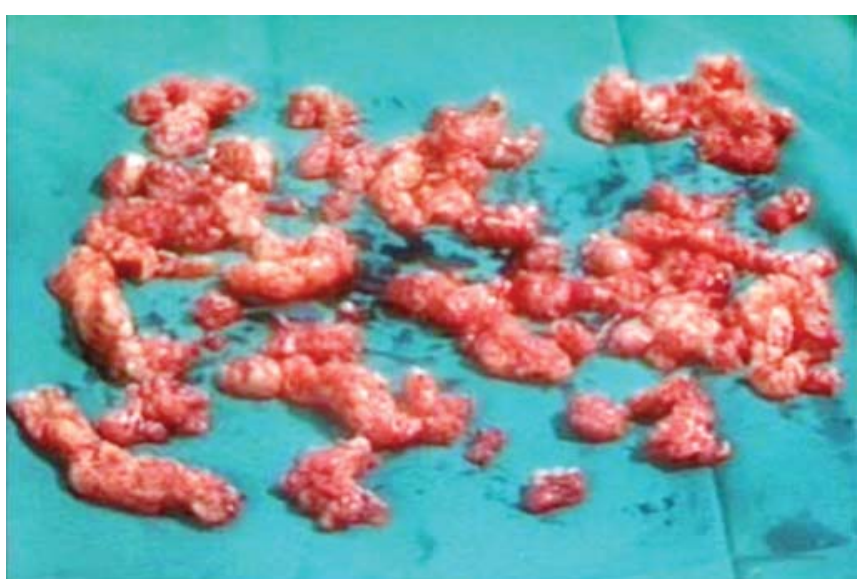

Fig. 6: Morcellated myoma pieces

interrupted sutures. Adhesion barrier was placed on the suture line.

The total blood loss was $150 \mathrm{ml}$. The time taken for surgery from the insertion of Veress to the last skin suture was 2 hours. Skin was sutured with 3-0 delayed absorbable subcuticular sutures. The total weight of the specimen was $400 \mathrm{gm}$. The specimen was sent for histopathological examination. The urinary catheter was removed after 12 hours. Patient was started on liquid diet 6 hours after the surgery. Postoperative period was uneventful. Histopathology report showed benign leiomyoma.

\section{DISCUSSION}

Hysteroscopic myomectomy is a therapeutic option for the treatment of submucous fibroids. However, transcervical resection of fibroids with deep intramural extension is performed only in selected patients. ${ }^{6}$ A major concern is that complete hysteroscopic resection might result in uterine perforation or fluid overload. As hysteroscopic myomectomy is at times a highly complex procedure, its real feasibility must be evaluated correctly preoperatively in order to minimize the morbidity and mortality that can occur during the procedure.

Conventionally, hysteroscopic myomectomy is not advisable if the myoma is larger than 5 or $6 \mathrm{~cm}$, if more than $50 \%$ of the endometrial surface is affected by myoma size or number, or if the size of the uterine cavity has been limited to that of 16 weeks of gestation or to 10,12 , or $15 \mathrm{~cm}^{7}$

Some authors have described two-stage hysteroscopic myomectomy for removal of large submucous fibroids. ${ }^{8}$ Myomas with the greatest diameter within the uterine wall have been associated with increased operating time and potential side effects, such as heavy hemorrhage, difficulty to control uterine perforation and water intoxication, and often require a secondstage operation to remove the myoma when the remaining portion of the submucous fibroid has been pushed into the uterine cavity by continuous myometrial contraction. ${ }^{9}$
In order to avert the complications of hysteroscopic myomectomy and avoid an incomplete excision, we perform laparoscopic myomectomy for patients with large submucous fibroids more than $5 \mathrm{~cm}$. In our patient, there were multiple fibroids more than $5 \mathrm{~cm}$. So, laparoscopic approach to remove these fibroids prevented the complications of hysteroscopy and intraoperative blood loss during laparoscopic removal was minimized by uterine artery ligation.

The concerns of laparoscopic removal of submucous fibroids are mainly: Opening the endometrial cavity, healing of suture line, possibility of subsequent pregnancy and risk of uterine rupture during pregnancy. The events leading to dehiscence are thought to include suboptimal suturing of the uterine incision and/or impaired wound healing from extensive use of coagulation or any tissue-destroying modality. ${ }^{10}$

Hence, laparoscopic myomectomy may be a treatment option for patients with submucous fibroids more than $5 \mathrm{~cm}$ size and if the uterine size is more than 16 weeks. This procedure prevents the risk of hysteroscopy complications like perforation and fluid overload. However, it has the disadvantage of leaving a uterine scar. Using the morcellator to enucleate the myoma from its bed may some times lead to inadvertent injury to the uterine wall. Ligating the uterine artery prior to the procedure will minimize the blood loss.

\section{REFERENCES}

1. Solomon Leigh A, Schimp Veronica L. Clinical update of smooth muscle tumors of the uterus. J Minimum Invasive Gynecol 2005;12:401-08.

2. Narayan R, Goswamy RK. Treatment of submucous fibroids and outcome of assisted conception. J Am Assoc Gynecol Laparosc 1994;1(4Pt1):307-11.

3. Sinha Manju, Hegde Aparna, Sinha Rakesh. Parotid area sign: A clinical test for the diagnosis of fluid overload in hysteroscopic surgery. J Minim Invasive Gynecol 2007;14:161-68.

4. Sinha Rakesh, Hegde A. Safe entry techniques during laparoscopy. J Minim Invasive Gynecol 2005;12:463-65.

5. Sinha Rakesh, Hegde Aparna, Warty Neeta, et al. Laparoscopic myomectomy: Enucleation of the myoma by morcellation while it is attached to the uterus. J Minimum Invasive Gynecology 2005;12:284-89.

6. Wamsteker K, Emanuel MH, de Kruif JH. Transcervical hysteroscopic resection of submucous fibroids for abnormal uterine bleeding: Results regarding the degree of intramural extension. Obstet Gynecol 1993;82:736-40.

7. Neuwirth RS. Hysteroscopic submucous myomectomy. Obstet Gynecol Clin North Am 1995;22:541-58.

8. Donnez J, Polet R, Smets M, Bassil S, Nisolle M. Hysteroscopic myomectomy. Curr Opin Obstet Gynecol 1995;7:311-16.

9. Crosignani PG, Vercellini P, Meschia M, Oldani S, Bramante T. GnRH agonists before surgery for uterine leiomyomas: A review. J Reprod Med 1996;41:415-21.

10. Frishman Gary N, Jurema Marcus W. Myomas and myomectomy. J Minimum Invasive Gynecology 2005;12:443-56. 


\section{Book Review}

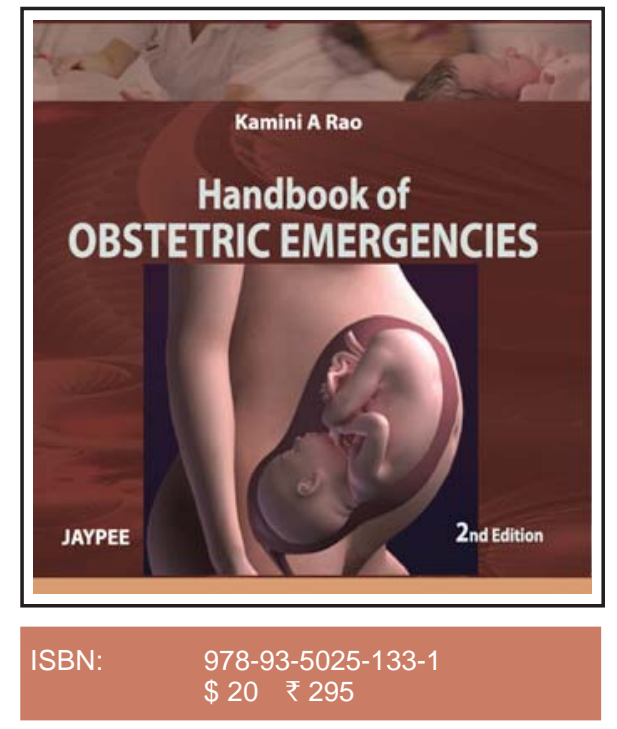

Publishers: Jaypee Brothers Medical Publishers (P) Ltd.

Also Available online at www.jaypeebrothers.com

\section{Handbook of Obstetric Emergencies}

The second edition of the Handbook of Obstetric Emergencies, published 2011, provides concise management guidelines for common obstetric problems encountered in clinical practice. It updates the first edition published in 2003.

It starts with a chapter on differential diagnosis of common complaints in pregnancy and goes on to discuss the obstetric as well as medical disorders complicating pregnancy. It covers topics like anaphylactic reactions and transfusion reactions that are practically useful. The clinical presentation, laboratory investigations and management are discussed. The text is bulleted and brief yet comprehensive. In a total of 150 pages it covers 40 chapters. It also provides
Kamini A Rao

DGO DORCP DCh MCh (UK) FRCOG (UK) FICOG FAIS PGDMLE (Law) President, FOGSI-2001

Medical Director, Bangalore Assisted Conception Centre (An ISO 9002 Organization) No. 6/7, Kumara Krupa Road, High Grounds Bengaluru, Karnataka, India a list of pregnancy laboratory reference values in the appendix.

The book is directed toward the practicing clinician at a primary health center or a rural semiurban setting. It will also serve as a quick reference for the postgraduates preparing for examinations. The price is nominal and the size is compact, so as to make it easy to carry to work.

Mala Arora

FRCOG, FICOG, FICMCH Director, NOBLE IVF Centre Sector-14, Faridabad, Haryana Consultant, Fortis La Femme S 549 GK 2, New Delhi, India 